\title{
Developmental stability of skull morphology in European bison Bison bonasus
}

\author{
Alexander S. BARANOV, Zdzisław PUCEK, Eugeniya G. KISELEVA \\ and Vladimir M. ZAKHAROV
}

Baranov A. S., Pucek Z., Kiseleva E. G. and Zakharov V. M. 1997. Developmental stability of skull morphology in European bison Bison bonasus. [In: Developmental homeostasis in natural populations of mammals: phenetic approach. V. M. Zakharov and A. V. Yablokov, eds]. Acta Theriologica, Suppl. 4: 79-85.

We compared developmental stability and total phenotypic diversity of 25 skull characters in three populations of European bison Bison bonasus (Linnaeus, 1758) Developmental stability was measured by fluctuating asymmetry, which was estimated by the variance of the left-right $(1-r)$ and scaled $(1-r) /(1+r)$ differences between the left (l) and right ( $r$ ) sides of the skull. Mean number of asymmetrical characters per individual was used as an integrated index of developmental stability. Total phenotypic variability was examined by variance of $(\mathrm{l}+\mathrm{r})$ for the same characters. Greater developmental instability and total phenotypic diversity were found in bison from Pszczyna Reserve and Białowieża Primeval Forest, as compared with those from Okskiï Reserve. This indicates the gradual deterioration of developmental stability in the following sequence of the studied populations: Okskiï Reserve, Białowieża Primeval Forest, Pszczyna Reserve. In the Białowieża population, deterioration of developmental stability could be detected, even though commonly used fitness measures showed no response. In the Pszczyna population, more serious developmental stability disturbance was accompanied by decreasead viability, an expression of inbreeding depression. Two samples taken from the Białowieża population at different times showed similar levels of developmental stability, which indicates the reliability of fluctuating asymmetry. These results suggest developmental stability to be an essential characteristic for monitoring populations and especially for revealing the initial response to stress.

N. K. Koltzov Institute of Developmental Biology, Russian Academy of Sciences, Vavilov Str. 26, Moscow 117808, Russia (ASB, VMZ); Mammal Research Institute, Polish Academy of Sciences, 17-230 Białowieża, Poland (ZP); Okskiï Reserve, p/o Lakash, Spasskii Raion, Ryzanskaya Oblast', Russia (EGK)

Key words: Bison bonasus, phenotypic diversity, fluctuating asymmetry, developmental stability, inbreeding

\section{Introduction}

The European bison Bison bonasus (Linnaeus, 1758) passed through a population bottleneck during World War I. Only 54 animals survived this critical period. Still, the whole extant species is treated as derived from a foundation herd of 13 animals, representing a recombination of only 12 diploid sets of genes (Slatis 1960, Olech 1989). Among the founders were animals of the lowland subspecies (Bison 
bonasus bonasus), originating from Białowieża Forest, and one bull of the other subspecies $(B . b$. caucasicus), from the Caucasus. Crossed to Białowieża females this bull started a separate genetical line of pure European bison, so called the Lowland-Caucasian line.

The species is now represented by several isolated populations of different sizes, either free-ranging or confined to nature reserves (Krysiak 1967, Flint and Pererva 1986, Pucek 1986, 1991). There are indications that inbreeding affects a number of demographic (Olech 1987) and morphological (Kobryńczuk 1985) characters in captive animals. This suggests that potential negative effects of inbreeding might also be observed in free-ranging populations. Genetic contributions of founders to the different wild populations are not fully understood. Knowing the inbreeding status of these populations is of great importance for the future management and conservation of this species. Comprehensive characterization of the condition of animals in particular populations is needed; in some cases highly homozygous populations can successfully persist for a long time, while in others adverse effects can be observed in the early generations of breeding (Mather 1943, 1953, Strunnikov 1994).

Developmental stability is an integrated, sensitive index of an organism's condition (Zakharov 1987, 1989). Its level can be detected by studying fluctuating asymmetry of morphological structures. High developmental stability corresponds to genetic coadaptation and optimal environmental conditions (Zakharov and Graham 1992, Zakharov and Clarke 1993, Markow 1994). Deterioration of developmental stability commonly takes place as a result of adverse changes in the genome, and particularly from a decrease in heterozygosity (Soulé 1979, Zakharov 1981, 1987, 1992, Leary et al. 1985, 1992, Zakharov et al. 1995).

In this study, we ask whether there are any differences in the level of developmental stability, as measured by fluctuating asymmetry of morphological characters of the skull of European bison Bison bonasus originating from different isolated populations and having different histories.

\section{Material and methods}

One hundred fifteen skulls of the European bison B. bonasus have been used for this study. Four samples from three populations were compared: (1) Okskiï Reserve, Russia $(n=29)$, (2) Białowieża Primeval Forest, Poland, collected between 1970 and $1986(n=34)$, and (3) collected between 1987 and $1988(n=29)$, (4) Pszczyna Reserve, Poland $(n=23)$. The material represented different genetical lines, recognized in recent world population of the species. Animals from Białowieża Forest belong to a pure Lowland line, originated from Bison bonasus bonasus. Those from Pszczyna constituted a daughter line of the same origin, but were kept isolated from the Białowieża population for several decades. Animals from the Okskii Reserve belonged to the Lowland-Caucasian line, being the crossings between lowland (B. b. bonasus) and mountain (B. b. caucasicus) subspecies of the European bison (cf Pucek 1986, 1991 for details). 


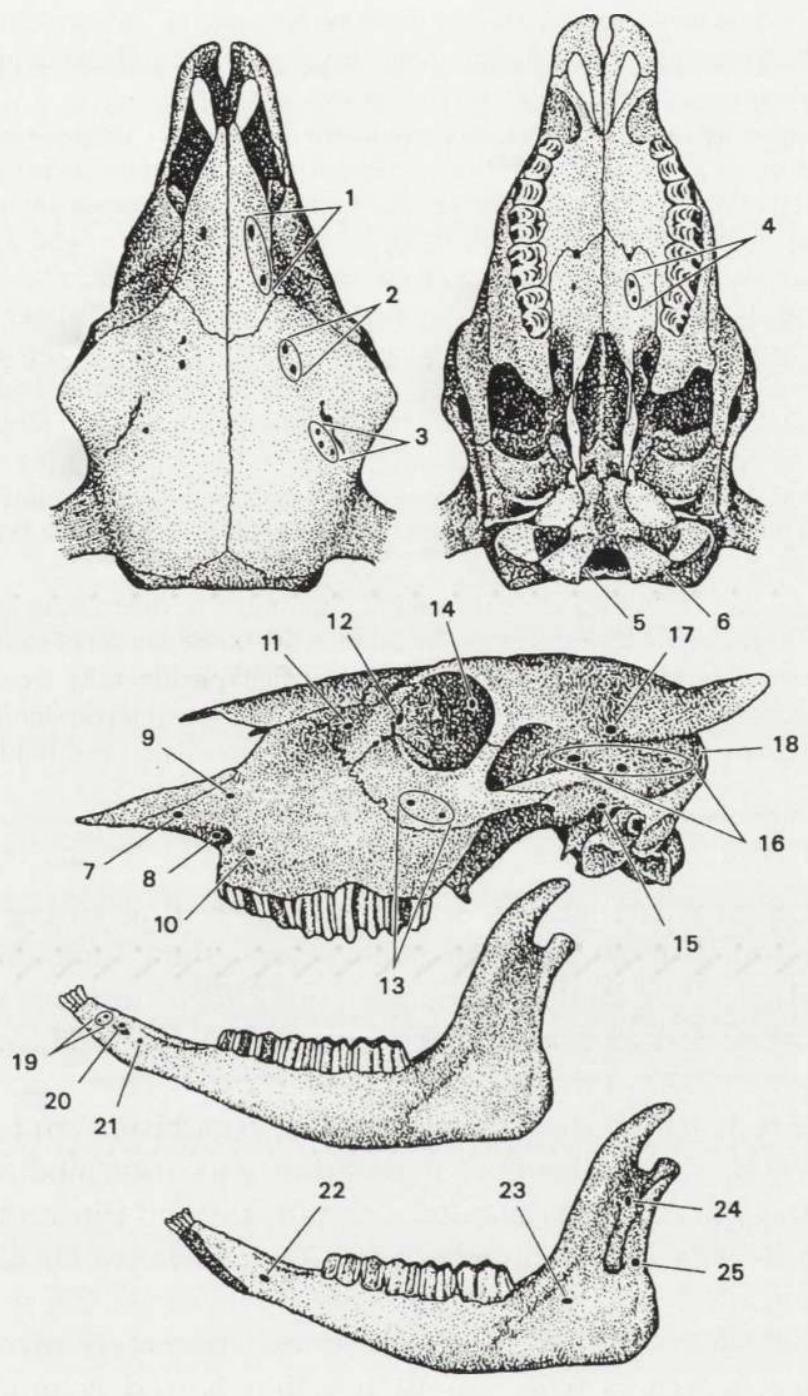

Fig. 1. Skull of the European bison Bison bonasus with 25 studied characters marked. The characters (number of foramina) are as follows: 1 - foramina on nasal bones, 2 - foramina in anterior part of supraorbital sulcus, 3 - foramina in posterior part of supraorbital sulcus, posteriorily to foramen supraorbitale posterior, 4 - foramina palatina minora, 5 - foramen nervi hypoglossi, 6 - foramen epicondylaris, 7 - foramen accessorius anterior canali infraorbitali, 8 -foramen accessorius internus canali infraorbitali, 9 - foramen accessorius superior canali infraorbitali, 10 - foramen accessorius posterior canali infraorbitali, 11 - additional foramen on lacrimal bone, 12 - foramen lacrimale, 13 foramina on zygomatic bone, 14 - foramina in outlet of supraorbital canal, 15 - foramen postglenoideum, 16 - foramina squamata temporalis, 17 - foramen frontale, 18 - parietal foramen, 19 additional foramina located anteriorily of foramen mentale, 20 - additional foramina in outlet of foramen mentale, 21 - foramen accessorius posterior of foramen mentale, 22 - foramen symphisis, 23 - foramen accessorius anterior foramen mandibulare, 24 - foramen accessorius superior foramen mandibulare, 25 --foramen accessorius posterior foramen mandibulare. 
Skull material is preserved at the Okskii Reserve (sample 1), in collections of the Mammal Research Institute PAS (samples 2 and 3) and in the European Bison Museum at the Department of Animal Anatomy, Warsaw Agricultural University, Warsaw (sample 4).

Twenty five morphological characters, the number of foramina for nerves and blood vessels (Fig. 1), were scored on each skull. Fluctuating asymmetry, as the main measure of developmental stability, was calculated for each character as the variance of difference in number of foramina between the left and right sides of the skull (l-r). As no significant sex and age differences were found, the whole samples were used for comparisons.

There were no indications of antisymmetry or directional asymmetry (Palmer and Strobeck 1986) in particular characters. The difference in the number of foramina between the left-right $(1-r)$ sides of the skull was considered to be fluctuating asymmetry. To exclude possible scale effects, variances were calculated for both the difference between number of foramina on two sides (l-r) as well as for the value of this difference divided by their sum $(l-r) /(1+r)$. All characters, as well as their asymmetries, were uncorrelated with each other. Single significant values of correlation coefficient found in all possible paired comparisons of the characters ( 5 of 300) can be ascribed to type I statistical error (Sokal and Rohlf 1981).

We used sums of ranks to investigate intersample differences in fluctuating asymmetry variance. The mean number of asymmetric characters per individual, for the whole set of characters, was used as an integrated measure of developmental stability. Total phenotypic diversity for the same characters was estimated by variance for $(l+r)$. The Student's $t$-statistics, non-parametric sign-test and Friedman's test were used to assess the significance of intersample differences (Sokal and Rohlf 1981).

\section{Results}

The variance for both $(1-r)$ and scaled $(1-r) /(1+r)$ fluctuating asymmetry, as well as a mean number of asymmetrical characters, show high similarity for both samples collected from the Białowieża population. Mean number of asymmetrical characters was $10.62 \pm 0.43$ for the early sample (1970-1986) and $10.44 \pm 0.58$ for the later sample (1987-1988).

Asymmetry was least in the Okskiï Reserve population and greatest in the Pszczyna population; the Białowieża population was intermediate (Table 1). A non-parametric Friedman's test revealed a significant and concordant intersample variation in both fluctuating asymmetry variances: variance for difference (27.92, $p<0.001)$ and variance for difference devided by sum $(16.22, p<0.001)$ for all characters studied. Mean number of asymmetrical characters revealed significant intersample difference $(p<0.05)$ in all possible paired comparisons of three populations under study.

Table 1. Integrated measures of developmental stability (NA, A and B) and phenotype diversity (C) for 25 characters of skull morphology (Fig. 1) in the samples from three different populations of European bison Bison bonasus. NA - mean number of asymmetrical characters, A - sum of ranks for variance $(1-r), B-$ sum of ranks for variance $(1-r) /(l+r), C-$ sum of ranks for variance $(l+r)$.

\begin{tabular}{lcccc}
\hline Population & $\mathrm{NA} \pm \mathrm{SE}$ & $\mathrm{A}$ & $\mathrm{B}$ & $\mathrm{C}$ \\
\hline Okskiï Reserve & $6.31 \pm 0.61$ & 30 & 34.5 & 38 \\
Białowieża Forest (1970-1988) & $10.46 \pm 0.37$ & 53 & 53 & 50.5 \\
Pszczyna Reserve & $11.78 \pm 0.52$ & 67 & 62.5 & 61.5 \\
\hline
\end{tabular}


The total phenotypic diversity measured by variance for sum revealed the same pattern of interpopulation difference (Table 1). The Friedman's test is equal to $11.06(p<0.01)$.

\section{Discussion}

Disturbance of developmental stability, indicating changes in an organism's condition, commonly takes place under environmental or genetic stress (Ruban and Zakharov 1984, Zakharov 1989, Zakharov and Sikorski 1997). Many populations of species in large areas having undisturbed conditions are characterized by similar levels of developmental stability (Zakharov 1987, 1989). For the Okskii Reserve and Białowieża populations of European bison, we do not have any reason to suspect stressful environmental conditions.

From the genetic perspective, changes in developmental stability correspond to genotypic changes. Thus, developmental stability occurs under increased homozygosity (Soulé 1979, Kat 1982, Leary et al. 1985, 1992, Zakharov et al. 1995). Deterioration of developmental stability in these cases is a manifestation of inbreeding depression. This measure of inbreeding depression indicates the initial changes in an organism's condition that could not yet affect the other commonly used fitness parameters.

It seems most probable that the differences among European bison populations could have a genetic explanation. Animals within each of these populations breed freely. These populations are derived from a limited number of founders. The Białowieża free-ranging population originated from the captive animals released into Białowieża Forest, and containing genes of all 7 founders of the Lowland line. Animals bred in the Okskii Reserve contain genes of 9 founders (out of a total of 12) composing the Lowland-Caucasian line (Olech 1989).

The original genetic diversity of the Białowieża population could be less than that of the Okskii Reserve population, because of the hybrid origin of the latter. The lover developmental stability of the Białowieża population is probably a result of its greater homozygosity, as compared with the Okskiï Reserve population (Olech 1989, Hartl and Pucek 1994, Udina et al. 1994, Sipko et al. 1995).

Our data demonstrate that greater phenotypic diversity in the Białowieża population, as compared with the Okskiï Reserve population, is accompanied by an increase of fluctuating asymmetry. Thus, increased phenotypic diversity in the Białowieża population is caused not by genetic diversity (it actually decreases), but by increased developmental noise (Zakharov 1987, 1989).

The great similarity of the fluctuating asymmetry estimates for two samples collected from the Białowieża Forest population at different times is evidence for the stability of the situation there and for the reliability of the developmental homeostasis estimates. A gradual asymmetry increase indicates a corresponding developmental stability decrease in the following population sequence: Okskiï 
Reserve - Białowieża Forest - Pszczyna Reserve. This suggests that the intermediate level of developmental stability in the Białowieża population is a result of decreased heterozygosity. And the higher level of inbreeding in the Pszczyna Reserve population is accompanied by a more serious deterioration of its developmental stability.

Developmental stability study is essential for characterizing the condition of populations. Decreased developmental stability in the Białowieża population is not yet accompanied by any obvious changes in the viability of animals (Pucek et al. 1996). In contrast, the more serious deterioration of developmental stability in the Pszczyna population is already accompanied by an obvious manifestation of the inbreeding depression. This demonstrates an opportunity to distinguish even initial changes in an organism's condition that can not be revealed by other commonly used measures of fitness.

A larger scale screening of various populations for fluctuating asymmetry could provide a comprehensive characterization of the situation for the European bison, and for other rare or endangered species. A basic question whether a particular genetic change, caused by inbreeding, outbreeding, or selection, affects the condition of an organism. An advantage of fluctuating asymmetry is the opportunity to get information on an organism's condition even through the study of museum collections.

Acknowledgments: This work was conducted within the framework of the bilateral agreement between Russian and Polish Academies of Sciences. We are grateful to Mr S. Buszko, who assisted in using skull collection of the Mammal Research Institute (MRI) PAS, Białowieża. Scientific staff of the MRI is acknowledged for stimulating discussion of the results. Many thanks are due to Dr J. H. Graham of Berry College, Georgia, USA, for correcting our language.

\section{References}

Flint V. and Pererva V. 1986. [The perspectives of increase in the number of bison in the USSR]. Hunt and hunting economy 3: 4-7. [In Russian]

Hartl G. B. and Pucek Z. 1994. Genetic depletion in the European bison (Bison bonasus) and the significance of electrophoretic heterozygosity for conservation. Conservation biology 8: 167-174.

Kat P. W. 1982. The relationship between heterozygosity for enzyme loci and developmental homeostasis in peripheral populations of aquatic bivalves (Unionidae). American Naturalist 119: $824-832$.

Kobryńczuk F. 1985. The influence of inbreeding on the shape and size of the skeleton of the European bison. Acta Theriologica 30: 379-422.

Krysiak K. 1967. The history of the European bison in the Białowieża Forest and the results of its protection. Acta Theriologica 12: 323-331.

Leary R. F., Allendorf F. W. and Knudsen K. L. 1985. Developmental instability as an indicator of reduced genetic variation in hatchery trout. Transactions of the American Fisheries Society 114: $230-235$

Leary R. F., Allendorf F. W. and Knudsen K. L. 1992. Genetic, environmental, and developmental causes of meristic variation in rainbow trout. Acta Zoologica Fennica 191: 79-95.

Markow T. A. (ed). 1994. Developmental instability: its origins and evolutionary implications. Kluwer Academic Publishers, Dordrecht: 1-440. 
Mather K. 1943. Polygenetic inheritance and natural selection. Biological Reviews 18: 32-64.

Mather K. 1953. Genetical control of stability in development. Heredity 7: 297-336.

Olech W. 1987. Analysis of inbreeding in European bison. Acta Theriologica 30: 373-387.

Olech W. 1989. The participation of ancestral genes in the existing population of European bison. Acta Theriologica 34: 397-407.

Palmer R. A. and Strobeck C. 1986. Fluctuating asymmetry: measurement, analysis, patterns. Annual Review in Ecology and Systematics 17: 391-421.

Pucek Z. 1986. Bison bonasus (Linnaeus, 1758) - Wisent. [In: Handbuch der Säugetiere Europas. Paarhufer 2/II. J. Niethammer and F. Krapp, eds]. Aula Verlag, Wiesbaden: 287-315.

Pucek Z. 1991. History of the European bison and problems of its protection and management. [In: Global trends in wildlife management. B. Bobek, K. Perzanowski and W. Regelin, eds]. Transactions of 18th IUGB Congress, Kraków 1987. Swiat Press, Kraków-Warszawa: 19-39.

Pucek Z., Seal U. S. and Miller P. (eds) 1996. Population and habitat viability assessment for the European bison (Bison bonansus). IUCN/SSC Conservation Breeding Specialist Group: Apple Valey, Minnesota, USA: 1-138.

Ruban G. I. and Zakharov V. M. 1984. [Comparison of rapid- and slow-growing forms of the roach (Rutilus rutilus) according to developmental stability]. Doklady Akademii Nauk SSSR 277: 1510-1512. [In Russian]

Sipko T. P., Rautian G. S., Udina I. G., Ukhanov S. V. and Berendyaeva Z. I. 1995. Investigation of blood group polymorphism in aurochs [sic!] (Bison bonasus). Genetika 31: 93-100. [In Russian with English summary]

Slatis H. M. 1960. An analysis of inbreeding in the European bison. Genetics 45: 275-287.

Sokal R. R. and Rohlf F. J. 1981. Biometry. Freeman, San-Francisco: 1-859.

Soulé M. E. 1979. Heterozygosity and developmental stability: another look. Evolution 33: 396-401.

Strunnikov V. A. 1994. [The nature of heterosis and new methods of its increase]. Nauka, Moscow: 1-108. [In Russian]

Udina I. G., Sokolova S. S., Sipko T. P. and Sulimova G. E. 1994. Comparative analysis of polymorphism for DQB and DRB DNA loci of the major histocompatibility in representatives of family Bovidae. Genetika 30: 356-360. [In Russian with English summary]

Zakharov V. M. 1981. Fluctuating asymmetry as an index of developmental homeostasis. Genetika (Beograd) 13: 241-256.

Zakharov V. M. 1987. [Animal asymmetry: population-phenogenetic approach.] Nauka, Moscow: 1-216. [In Russian]

Zakharov V. M. 1989. Future prospects for population phenogenetics. Soviet Science Reviews, Section F 4 (3): 1-79.

Zakharov V. M. 1992. Population phenogenetics: Analysis of developmental stability in natural populations. Acta Zoologica Fennica 191: 7-30.

Zakharov V. M. and Clarke G. M. (eds) 1993. Biotest: a new integrated biological approach for assessing the condition of natural environments. Moscow Affiliate of the International Biotest Foundation, Moscow: 1-60.

Zakharov V. M. and Graham J. H. (eds) 1992. Developmental stability in natural populations. Acta Zoologica Fennica 191: 1-200.

Zakharov V. M., Shchepotkin D. V. and Strunnikov V. A. 1995. [The heterozygosity and temperature impact on the developmental stability of silkworm (Bombics mori)]. Doklady Akademii Nauk 340: 430-432. [In Russian]

Zakharov V. M. and Sikorski M. D. 1997. Inbreeding and developmental stability in a laboratory strain of the bank vole Clethrionomys glareolus. [In: Developmental homeostasis in natural populations of mammals: phenetic approach. V. M. Zakharov and A. V. Yablokov, eds]. Acta Theriologica, Suppl. 4: 73-78. 